\title{
SIFAT-SIFAT OPERASI HADAMARD PADA MATRIKS
}

\author{
SOVIA ARMA, YANITA, NOVA NOLIZA BAKAR \\ Program Studi Matematika, \\ Fakultas Matematika dan Ilmu Pengetahuan Alam, Universitas Andalas, \\ Kampus UNAND Limau Manis Padang, Indonesia. \\ email : soviaarma6@gmail.com
}

\begin{abstract}
Abstrak. Tulisan ini membahas tentang sifat-sifat operasi Hadamard pada matriks, dimana operasi Hadamard merupakan operasi perkalian elemen-elemen yang bersesuaian dari dua matriks $A$ dan $B$ yang berukuran sama. Sifat-sifat operasi Hadamard yang dibahas pada tulisan ini adalah sifat-sifat dasar operasi Hadamard dan sifat-sifat operasi Hadamard terhadap definit positif dan definit taknegatif.

Kata Kunci: Matriks, Operasi Hadamard, Sifat-Sifat Dasar, Definit Positif, Definit Taknegatif

$\begin{array}{lll}\text { Diterima } & : & 29 \text { November } 2018 \\ \text { Direvisi } & : & 3 \text { Desember } 2018 \\ \text { Dipublikasikan } & : & 30 \text { Desember } 2018\end{array}$
\end{abstract}

\section{Pendahuluan}

Operasi Hadamard merupakan salah satu operasi pada matriks yang berguna dalam bidang statistik. Operasi Hadamard ini dipopulerkan oleh matematikawan Prancis, yaitu Jacques Hadamard. Kemudian dirujuk oleh Styan sekitar tahun 1973, serta Hom dan Johnson sekitar tahun 1991 [5]. Pada tugas akhir ini akan dibahas tentang operasi Hadamard dan juga sifat-sifat operasi Hadamard pada matriks. Jika diberikan matriks $A$ dan $B$ yang berukuran $m \times n$, maka akan dilihat bagaimana sifat-sifat dari operasi Hadamard pada matriks.

\section{Tinjauan Teori}

\subsection{Teori Matriks}

Definisi 2.1. [1] Suatu matriks yang semua entrinya adalah nol disebut matriks nol yang disimbolkan dengan $O$.

Definisi 2.2. [7] Suatu matriks A berukuran $n \times n$ dikatakan matriks diagonal, apabila entri-entri selain diagonal utama bernilai nol. Matriks diagonal dari A dapat dinyatakan sebagai $A=\operatorname{diag}\left(a_{11}, a_{22}, \cdots, a_{n n}\right)$.

Definisi 2.3. [1] Suatu matriks A berukuran $m \times m$ adalah simetri, jika

$$
A=A^{T} \text {. }
$$


Definisi 2.4. [6] Suatu matriks A berukuran $n \times n$ dikatakan taksingular atau dapat dibalik (invertible) jika terdapat matriks $B$ sehingga $A \cdot B=B \cdot A=I$. Matriks $B$ disebut sebagai invers dari $A$.

Definisi 2.5. [6] Suatu matriks $n \times n$ dikatakan singular jika tidak memiliki invers.

Definisi 2.6. [1] Rank dari suatu matriks $A \in \mathbb{R}^{n \times n}$ adalah banyaknya baris yang masih memuat entri tidak sama dengan nol setelah diperoleh bentuk eselon baris tereduksi dari A.

\subsection{Nilai Eigen dan Vektor Eigen}

Definisi 2.7. Jika $A$ adalah matriks berukuran $n \times n$, maka vektor tak nol $\boldsymbol{x}$ disebut vektor eigen dari $A$ jika Ax adalah kelipatan skalar dari $\boldsymbol{x}$, yaitu

$$
A \boldsymbol{x}=\lambda \boldsymbol{x},
$$

untuk suatu $\lambda$. Skalar $\lambda$ disebut nilai eigen dari $A$ dan $\boldsymbol{x}$ disebut sebagai vektor eigen dari $A$ yang terkait dengan $\lambda$.

\subsection{Dekomposisi Spektral}

Teorema 2.8. [7] Misalkan $A$ adalah matriks simetri berukuran $m \times m$ dengan nilai eigen $\lambda_{1}, \lambda_{2}, \cdots, \lambda_{m}$ dan misalkan bahwa $\boldsymbol{x}_{1}, \boldsymbol{x}_{2}, \cdots, \boldsymbol{x}_{m}$ adalah suatu himpunan vektor eigen ortonormal yang bersesuaian dengan nilai eigennya. Kemudian, jika $\Lambda=\operatorname{diag}\left(\lambda_{1}, \lambda_{2}, \cdots, \lambda_{m}\right)$ dan $X=\left[\begin{array}{llll}\boldsymbol{x}_{1} & \boldsymbol{x}_{2} \cdots \boldsymbol{x}_{m}\end{array}\right]$, maka

$$
A=X \cdot \Lambda \cdot X^{T} \text {. }
$$

\subsection{Matriks Definit Positif dan Definit Taknegatif}

Definisi 2.9. [2] Bentuk kuadrat dari $x_{1}, x_{2}, \cdots, x_{n}$ dapat ditulis dalam bentuk

$$
\left[\begin{array}{llll}
x_{1} & x_{2} & \cdots & x_{n}
\end{array}\right] A\left[\begin{array}{c}
x_{1} \\
x_{2} \\
\vdots \\
x_{n}
\end{array}\right]
$$

dengan $A$ adalah matriks $n \times n$.

Definisi 2.10. [2] Bentuk kuadrat $\boldsymbol{x}^{T} A \boldsymbol{x}$ disebut definit positif, jika $\boldsymbol{x}^{T} A \boldsymbol{x}>0$ untuk semua $\boldsymbol{x} \neq \boldsymbol{O}$, dan matriks simetri $A$ disebut sebagai matriks definit positif, jika $\boldsymbol{x}^{T} A \boldsymbol{x}$ adalah bentuk kuadrat yang definit positif.

Teorema 2.11. [2] Suatu matriks simetri A dikatakan definit positif jika dan hanya jika determinan setiap submatriks utamanya adalah positif.

Suatu matriks simetri $A$ yang berukuran $n \times n$ adalah matriks definit positif yang memiliki sifat-sifat sebagai berikut $[6]$ : 
(a) A matriks taksingular,

(b) Determinan setiap submatriks utama dari $A$ adalah positif,

(c) $A$ dapat difaktorkan ke dalam suatu hasilkali $L L^{T}$, dimana $L$ adalah matriks segitiga bawah dengan elemen-elemen diagonal positif (dekomposisi Cholesky).

Suatu matriks simetri $A$ dan bentuk kuadrat $\boldsymbol{x}^{T} A \boldsymbol{x}$ disebut semidefinit positif, jika $\boldsymbol{x}^{T} A \boldsymbol{x} \geq 0$ untuk semua $\boldsymbol{x}$. Matriks $A$ adalah semidefinit positif jika dan hanya jika semua submatriks utamanya memiliki determinan yang taknegatif [2].

Istilah definit taknegatif akan digunakan untuk menunjukkan suatu matriks simetri yang definit positif atau semidefinit positif [5].

Teorema 2.12. [7] Misalkan A adalah matriks definit positif berukuran $m \times m$ dan didefinisikan

$$
A_{\alpha}=A-\alpha e_{1} e_{1}^{T},
$$

dimana $\alpha=|A| /\left|A_{1}\right|$ dan $A_{1}$ merupakan submatriks dari $A$ yang berukuran ( $m-$ $1) \times(m-1)$ yang dibentuk dengan menghapus baris dan kolom pertamanya, maka $A_{\alpha}$ adalah definit taknegatif.

\section{Sifat-Sifat Operasi Hadamard pada Matriks}

Definisi 3.1. [8] Operasi Hadamard terhadap dua matriks $A=\left[a_{i j}\right]$ dan $B=\left[b_{i j}\right]$ yang masing-masing berukuran $m \times n$ didefinisikan sebagai

$$
A \odot B=\left[\begin{array}{cccc}
a_{11} b_{11} & a_{12} b_{12} & \cdots & a_{1 n} b_{1 n} \\
a_{21} b_{21} & a_{22} b_{22} & \cdots & a_{2 n} b_{2 n} \\
\vdots & \vdots & \ddots & \vdots \\
a_{m 1} b_{m 1} & a_{m 2} b_{m 2} & \cdots & a_{m n} b_{m n}
\end{array}\right]
$$

atau

$$
A \odot B=\left[a_{i j} b_{i j}\right],
$$

dengan $i=1,2, \cdots, m$ dan $j=1,2, \cdots, n$.

Contoh 3.2. Misalkan matriks $A$ dan $B$ berukuran $2 \times 3$, dengan

$$
A=\left[\begin{array}{lll}
1 & 4 & 2 \\
0 & 2 & 3
\end{array}\right] \text { dan } B=\left[\begin{array}{lll}
3 & 1 & 3 \\
6 & 5 & 1
\end{array}\right]
$$

maka hasil dari $A \odot B$ adalah

$$
A \odot B=\left[\begin{array}{lll}
3 & 4 & 6 \\
0 & 10 & 3
\end{array}\right] .
$$

\subsection{Sifat-Sifat Dasar Operasi Hadamard}

Berikut ini adalah sifat-sifat dasar yang terkait dengan definisi operasi Hadamard, yaitu:

Teorema 3.3. [7] Misalkan A, B, dan $C$ adalah matriks berukuran $m \times n$, dengan entri-entri pada bilangan riil atau kompleks, maka: 
(a) $A \odot B=B \odot A$ (sifat komutatif),

(b) $(A \odot B) \odot C=A \odot(B \odot C)$ (sifat asosiatif),

(c) $(A+B) \odot C=A \odot C+B \odot C$ (sifat distributif kanan),

(d) $(A \odot B)^{T}=A^{T} \odot B^{T}$ (sifat transpos),

(e) $A \odot(O)=(O)$ (sifat perkalian dengan matriks nol),

(f) $A \odot\left(\mathbf{1}_{m} \cdot \mathbf{1}_{n}^{T}\right)=A$, dengan $\mathbf{1}_{m}$ dan $\mathbf{1}_{n}$ adalah vektor berukuran $m \times 1$ dan $n \times 1$, dengan semua entri adalah 1 ,

(g) Jika $m=n, A \odot I_{m}=D_{A}=\operatorname{diag}\left(a_{11}, a_{22}, \cdots, a_{m m}\right)$, dengan $I_{m}$ adalah matriks identitas berukuran $m \times m$,

(h) $C \cdot(A \odot B)=(C \cdot A) \odot B=A \odot(C \cdot B)$ dan $(A \odot B) \cdot C=(A \cdot C) \odot B=A \odot(B \cdot C)$, jika $m=n$ dan $C$ adalah matriks diagonal,

(i) $\left(\boldsymbol{a} \cdot \boldsymbol{b}^{T}\right) \odot\left(\boldsymbol{c} \cdot \boldsymbol{d}^{T}\right)=(\boldsymbol{a} \odot \boldsymbol{c}) \cdot(\boldsymbol{b} \odot \boldsymbol{d})^{T}$, dengan $\boldsymbol{a}$ dan $\boldsymbol{c}$ adalah vektor $m \times 1, \boldsymbol{b}$ dan $\boldsymbol{d}$ adalah vektor $n \times 1$.

Teorema 3.4. [7] Misalkan $A$ dan $B$ adalah matriks $m \times n, \boldsymbol{x}$ dan $\boldsymbol{y}$ masing-masing adalah vektor $m \times 1$ dan $n \times 1$, maka berlaku:

(a) $\mathbf{1}_{m}^{T} \cdot(A \odot B) \cdot \mathbf{1}_{n}=\operatorname{tr}\left(A \cdot B^{T}\right)$,

(b) $\boldsymbol{x}^{T} \cdot(A \odot B) \cdot \boldsymbol{y}=\operatorname{tr}\left(D_{x} \cdot A \cdot D_{y} \cdot B^{T}\right)$, dengan $D_{x}=\operatorname{diag}\left(x_{1}, x_{2}, \cdots, x_{m}\right)$ dan $D_{y}=\operatorname{diag}\left(y_{1}, y_{2}, \cdots, y_{n}\right)$.

\subsection{Sifat-Sifat Operasi Hadamard terhadap Definit Positif dan Definit Taknegatif}

Pada subbab ini akan dibahas sifat-sifat operasi Hadamard yang terkait dengan definit positif dan definit taknegatif. Sifat-sifat ini disajikan dalam bentuk teorema sebagai berikut.

Teorema 3.5. [7] Misalkan A dan B masing-masing adalah matriks simetri $m \times m$, maka berlaku:

(a) $A \odot B$ adalah definit taknegatif, jika $A$ dan $B$ adalah definit taknegatif,

(b) $A \odot B$ adalah definit positif, jika $A$ dan $B$ adalah definit positif.

Bukti. Misalkan $A$ dan $B$ adalah matriks simetri $m \times m$.

(a) Misalkan $A$ dan $B$ definit taknegatif, akan ditunjukkan $A \odot B$ juga definit taknegatif. Sebelum itu perlu ditunjukkan bahwa $A \odot B$ adalah matriks simetri, yaitu dengan menunjukkan $A \odot B=(A \odot B)^{T}$. Oleh karena $A$ dan $B$ adalah matriks-matriks simetri, maka berdasarkan Definisi $2.3 A=A^{T}$ dan $B=B^{T}$. Perhatikan bahwa:

$$
A \odot B=A^{T} \odot B^{T}=(A \odot B)^{T},
$$

sehingga jelas bahwa jika $A$ dan $B$ adalah matriks-matriks simetri, maka $A \odot B$ juga matriks simetri.

Selanjutnya, oleh karena $B$ definit taknegatif, maka $B$ adalah matriks simetri, sehingga berdasarkan Teorema $2.8 B=X \cdot \Lambda \cdot X^{T}=\left[b_{i j}\right]$, dengan 
$b_{i j}=\sum_{k=1}^{m} \lambda_{k} x_{i k} x_{j k}$, dimana $\lambda_{k} \geq 0$ untuk semua $k$. Akibatnya, untuk sebarang vektor $\boldsymbol{y}$ berukuran $m \times 1$ diperoleh

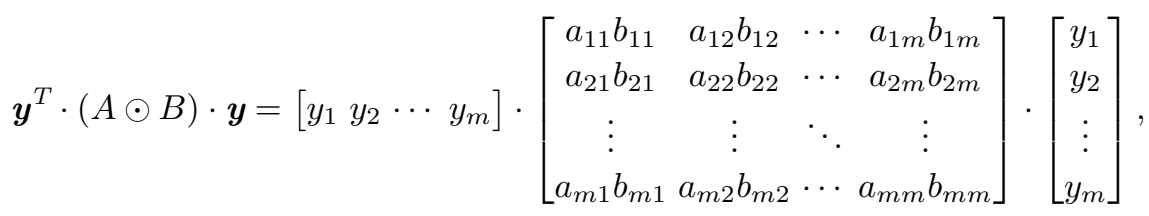

dengan $a_{i j}=a_{j i}$,

$$
\begin{aligned}
= & y_{1}\left(a_{11} b_{11} y_{1}+a_{12} b_{12} y_{2}+\cdots+a_{1 m} b_{1 m} y_{m}\right)+y_{2}\left(a_{21} b_{21} y_{1}+a_{22} b_{22} y_{2}+\cdots+\right. \\
& \left.a_{2 m} b_{2 m} y_{m}\right)+\cdots+y_{m}\left(a_{m 1} b_{m 1} y_{1}+a_{m 2} b_{m 2} y_{2}+\cdots+a_{m m} b_{m m} y_{m}\right) \\
= & \sum_{k=1}^{m} \sum_{i=1}^{m} \sum_{j=1}^{m} a_{i j}\left(\lambda_{k} x_{i k} x_{j k}\right) y_{i} y_{j} \\
= & \sum_{k=1}^{m} \lambda_{k}\left(y_{1} x_{1 k}\left(a_{11} y_{1} x_{1 k}+a_{12} y_{2} x_{2 k}+\cdots+a_{1 m} y_{m} x_{m k}\right)+y_{2} x_{2 k}\left(a_{21} y_{1} x_{1 k}+\right.\right. \\
& \left.a_{22} y_{2} x_{2 k}+\cdots+a_{2 m} y_{m} x_{m k}\right)+\cdots+y_{m} x_{m k}\left(a_{m 1} y_{1} x_{1 k}+a_{m 2} y_{2} x_{2 k}+\cdots+\right. \\
& \left.a_{m m} y_{m} x_{m k}\right) \\
= & \sum_{k=1}^{m} \lambda_{k}\left(\left[\begin{array}{c}
y_{1} \\
y_{2} \\
\vdots \\
y_{m}
\end{array}\right] \odot\left[\begin{array}{c}
x_{1 k} \\
x_{2 k} \\
\vdots \\
x_{m k}
\end{array}\right]\right) \cdot\left[\begin{array}{cccc}
a_{11} & a_{12} & \cdots & a_{1 m} \\
a_{21} & a_{22} & \cdots & a_{2 m} \\
\vdots & \vdots & \ddots & \vdots \\
a_{m 1} & a_{m 2} & \cdots & a_{m m}
\end{array}\right] \cdot\left(\left[\begin{array}{c}
y_{1} \\
y_{2} \\
\vdots \\
y_{m}
\end{array}\right] \odot\left[\begin{array}{c}
x_{1 k} \\
x_{2 k} \\
\vdots \\
x_{m k}
\end{array}\right]\right) \\
= & \sum_{k=1}^{m} \lambda_{k}\left(\boldsymbol{y} \odot \boldsymbol{x}_{k}\right)^{T} \cdot A \cdot\left(\boldsymbol{y} \odot \boldsymbol{x}_{k}\right),
\end{aligned}
$$

dimana $\boldsymbol{x}_{k}$ melambangkan kolom ke- $k$ dari $X$.

Oleh karena $A$ definit taknegatif, Persamaan (3.1) haruslah taknegatif, sehingga $A \odot B$ juga definit taknegatif.

(b) Misalkan $A$ dan $B$ definit positif, akan ditunjukkan $A \odot B$ juga definit positif. Jika A definit positif, maka Persamaan (3.1) akan bernilai positif untuk sebarang $\boldsymbol{y} \neq \mathbf{0}$ yang memenuhi $\boldsymbol{y} \odot \boldsymbol{x}_{k} \neq \mathbf{0}$ paling tidak untuk sebuah $k$, dimana $\lambda_{k}>0$. Akan tetapi, jika $B$ adalah definit positif, maka $\lambda_{k}>0$ untuk semua $k$ dan jika $\boldsymbol{y}$ memiliki komponen ke- $h$ dengan $\boldsymbol{y}_{h} \neq 0$, maka $\boldsymbol{y} \odot \boldsymbol{x}_{k}=\mathbf{0}$ untuk semua $k$ hanya jika baris ke- $h$ dari $X$ semuanya bernilai nol. Hal ini tidak mungkin karena $X$ matriks taksingular. Akibatnya, tidak ada $\boldsymbol{y} \neq \mathbf{0}$ yang menyebabkan Persamaan (3.1) sama dengan nol. Hal ini menunjukkan bahwa matriks $A \odot B$ adalah definit positif.

Teorema 3.6. [7] Misalkan $A$ dan $B$ adalah matriks simetri $m \times m$. Jika $B$ adalah definit positif dan $A$ adalah definit taknegatif dengan elemen diagonal positif, maka $A \odot B$ adalah definit positif. 
Bukti. Misalkan $A$ dan $B$ matriks simetri $m \times m, B$ definit positif dan $A$ definit taknegatif dengan elemen diagonal positif.

Akan ditunjukkan $A \odot B$ definit positif, yaitu dengan menunjukkan untuk sebarang $\boldsymbol{x} \neq \mathbf{0}, \boldsymbol{x}^{T} \cdot(A \odot B) \cdot \boldsymbol{x}>0$. Oleh karena $B$ definit positif, terdapat suatu matriks taksingular $P$ sedemikian sehingga $B=P \cdot P^{T}$. Selanjutnya, dari Teorema 3.4(b) diketahui bahwa

$$
\begin{aligned}
\boldsymbol{x}^{T} \cdot(A \odot B) \cdot \boldsymbol{x} & =\operatorname{tr}\left(D_{x} \cdot A \cdot D_{x} \cdot B^{T}\right) \\
& =\operatorname{tr}\left(D_{x} \cdot A \cdot D_{x} \cdot P \cdot P^{T}\right) \\
& =\operatorname{tr}\left(P^{T} \cdot D_{x} \cdot A \cdot D_{x} \cdot P\right)
\end{aligned}
$$

Oleh karena $A$ definit taknegatif, maka $D_{x} \cdot A \cdot D_{x}$ juga definit taknegatif. Selain itu, jika $\boldsymbol{x} \neq \mathbf{0}$, dan $A$ tidak memiliki elemen diagonal yang sama dengan nol, maka $D_{x} \cdot A \cdot D_{x} \neq(O)$. Hal ini berarti bahwa, $D_{x} \cdot A \cdot D_{x}$ memiliki rank setidaknya satu, sehingga memiliki setidaknya satu nilai eigen positif.

Oleh karena $P$ matriks taksingular, maka $\operatorname{rank}\left(D_{x} \cdot A \cdot D_{x}\right)=\operatorname{rank}\left(P^{T} \cdot D_{x}\right.$. $\left.A \cdot D_{x} \cdot P\right)$, sehingga $\left(P^{T} \cdot D_{x} \cdot A \cdot D_{x} \cdot P\right)$ juga definit taknegatif dengan setidaknya satu nilai eigen positif. Dengan demikian, dari Persamaan (3.2) dapat dinyatakan bahwa $\boldsymbol{x}^{T} \cdot(A \odot B) \cdot \boldsymbol{x}$ merupakan jumlah nilai eigen dari $P^{T} \cdot D_{x} \cdot A \cdot D_{x} \cdot P$.

Teorema 3.7. [7] Misalkan $A$ dan $B$ adalah matriks definit taknegatif $m \times m$, maka:

$$
|A| \prod_{i=1}^{m} b_{i i} \leq|A \odot B| .
$$

Bukti. Misalkan $A$ dan $B$ matriks definit taknegatif $m \times m$. Dalam hal ini, jika $A$ matriks singular, maka $|A|=0$, sedangkan $|A \odot B| \geq 0$ dijamin oleh Teorema 3.5 dan sifat definit taknegatif. Selanjutnya, untuk kasus dimana $A$ definit positif, pembuktian dilakukan dengan prinsip induksi matematika. Oleh karena $A$ dan $B$ definit taknegatif, maka $A$ dan $B$ harus matriks simetri. Misalkan

$$
P_{m}:|A| \prod_{i=1}^{m} b_{i i} \leq|A \odot B| .
$$

- Untuk $m=2$ diperoleh

$$
A=\left[\begin{array}{ll}
a_{11} & a_{12} \\
a_{12} & a_{22}
\end{array}\right] \text { dan } B=\left[\begin{array}{ll}
b_{11} & b_{12} \\
b_{12} & b_{22}
\end{array}\right],
$$

sehingga

$$
\begin{aligned}
|A \odot B| & =\left|\begin{array}{ll}
a_{11} b_{11} & a_{12} b_{12} \\
a_{12} b_{12} & a_{22} b_{22}
\end{array}\right| \\
& =|A| b_{11} b_{22}+a_{12}^{2}|B| \geq|A| b_{11} b_{22} .
\end{aligned}
$$

$\therefore P_{2}$ benar untuk $m=2$.

- Untuk membuktikan $P_{m}$ secara umum, asumsikan bahwa $P_{m}$ berlaku untuk $m-1$, 
sehingga diperoleh

$$
\left|A_{1}\right| \prod_{i=2}^{m} b_{i i} \leq\left|A_{1} \odot B_{1}\right|,
$$

dimana $A_{1}$ dan $B_{1}$ adalah submatriks dari $A$ dan $B$ yang dibentuk dengan menghapus baris pertama dan kolom pertama dari kedua matriks tersebut. Dari Teorema 2.12 diketahui bahwa $\left(A-\alpha e_{1} e_{1}^{T}\right)$ adalah definit taknegatif, dimana $\alpha=|A| /\left|A_{1}\right|$. Dengan demikian, menggunakan Teorema 3.5(a), 3.3(c), dan ekspansi formula untuk determinan diperoleh

$$
0 \leq\left|\left(A-\alpha e_{1} e_{1}^{T}\right) \odot B\right|=|A \odot B|-\alpha b_{11}\left|(A \odot B)_{1}\right|,
$$

dimana $(A \odot B)_{1}$ menunjukkan submatriks $(m-1) \times(m-1)$ dari $A \odot B$ yang dibentuk dengan menghapus baris dan kolom pertamanya. Oleh karena $(A \odot B)_{1}=A_{1} \odot B_{1}$, sehingga dari Persamaan (3.5), Persamaan (3.4), dan $\alpha\left|A_{1}\right|=|A|$ dapat dinyatakan bahwa

$$
|A \odot B| \geq \alpha b_{11}\left|A_{1} \odot B_{1}\right| \geq \alpha b_{11}\left(\left|A_{1}\right| \prod_{i=2}^{m} b_{i i}\right)=|A| \prod_{i=1}^{m} b_{i i} .
$$

\section{Kesimpulan}

(1) Sifat-sifat dasar operasi Hadamard, yaitu:

(a) Untuk matriks $A, B$ dan $C$ yang berukuran $m \times n$, dengan entri-entri pada bilangan riil atau kompleks berlaku:

(i) $A \odot B=B \odot A$ (sifat komutatif),

(ii) $(A \odot B) \odot C=A \odot(B \odot C)$ (sifat asosiatif),

(iii) $(A+B) \odot C=A \odot C+B \odot C$ (sifat distributif kanan),

(iv) $(A \odot B)^{T}=A^{T} \odot B^{T}$ (sifat transpos),

(v) $A \odot(O)=(O)$ (sifat perkalian dengan matriks nol),

(vi) $A \odot \mathbf{1}_{m} \cdot \boldsymbol{1}_{n}^{T}=A$, dengan $\boldsymbol{1}_{m}$ dan $\boldsymbol{1}_{n}$ adalah vektor berukuran $m \times 1$ dan $n \times 1$, dengan semua entri adalah 1 ,

(vii) Jika $m=n, A \odot I_{m}=D_{A}=\operatorname{diag}\left(a_{11}, A_{22}, \cdots, a_{m m}\right)$, dengan $I_{m}$ adalah matriks identitas berukuran $m \times m$,

(viii) $C \cdot(A \odot B)=(C \cdot A) \odot B=A \odot(C \cdot B) \operatorname{dan}(A \odot B) \cdot C=(A \cdot C) \odot B=$ $A \odot(B \cdot C)$, jika $m=n$ dan $C$ adalah matriks diagonal,

(ix) $\boldsymbol{a} \cdot \boldsymbol{b}^{T} \odot \boldsymbol{c} \cdot \boldsymbol{d}^{T}=(\boldsymbol{a} \odot \boldsymbol{c}) \cdot(\boldsymbol{b} \odot \boldsymbol{d})^{T}$, dengan $\boldsymbol{a}$ dan $\boldsymbol{c}$ adalah vektor $m \times 1$, $\boldsymbol{b}$ dan $\boldsymbol{d}$ adalah vektor $n \times 1$.

(b) Untuk matriks $A$ dan $B$ yang berukuran $m \times n, \boldsymbol{x}$ dan $\boldsymbol{y}$ masing-masing adalah vektor $m \times 1$ dan $n \times 1$ berlaku:

(i) $\mathbf{1}_{m}^{T} \cdot(A \odot B) \cdot \mathbf{1}_{n}=\operatorname{tr}\left(A \cdot B^{T}\right)$,

(ii) $\mathbf{x}^{T} \cdot(A \odot B) \cdot \mathbf{y}=\operatorname{tr}\left(D_{x} \cdot A \cdot D_{y} \cdot B^{T}\right)$, dengan $D_{x}=\operatorname{diag}\left(x_{1}, x_{2}, \cdots, x_{m}\right)$ $\operatorname{dan} D_{\boldsymbol{y}}=\operatorname{diag}\left(y_{1}, y_{2}, \cdots, y_{n}\right)$.

(2) Sifat-sifat operasi Hadamard terhadap definit positif dan definit taknegatif, yaitu:

(a) Jika $A$ dan $B$ matriks simetri $m \times m$, maka berlaku: 
(i) $A \odot B$ adalah definit taknegatif, jika $A$ dan $B$ juga definit taknegatif,

(ii) $A \odot B$ adalah definit positif, jika $A$ dan $B$ juga definit positif.

(b) Misalkan $A$ dan $B$ matriks simetri $m \times m$. Jika $B$ adalah definit positif dan $A$ adalah definit taknegatif dengan elemen diagonal positif, maka $A \odot B$ adalah definit positif.

(c) Jika $A$ dan $B$ matriks definit taknegatif $m \times m$, maka:

$$
|A| \prod_{i=1}^{m} b_{i i} \leq|A \odot B| .
$$

\section{Ucapan Terima kasih}

Penulis mengucapkan terima kasih kepada Bapak Prof. Dr. I Made Arnawa, Ibu Monika Rianti Helmi, M.Si, dan Bapak Zulakmal, M.Si yang telah memberikan masukan dan saran dalam penyempurnaan penulisan artikel ini.

\section{Daftar Pustaka}

[1] Anton, H dan C. Rorres. 2004. Aljabar Linier Elementer. Edisi Kedelapan. Erlangga, Jakarta

[2] Anton, H dan C. Rorres. 2005. Aljabar Linier Elementer. Edisi Kedelapan. Erlangga, Jakarta

[3] Herstein, I.N. 2000. Topics in Algebra. Second Edition. John Wiley \& Sons, Singapore

[4] Imrona, M. 2009. Aljabar Linier Dasar. Erlangga, Bandung

[5] Jacob, B. 1990. Linier Algebra. W. H. Freeman and Company, New York

[6] Leon, S.J. 2001. Aljabar Linier dan Aplikasinya. Edisi Kelima. Erlangga, Jakarta

[7] Schott, J.R. 1997. Matrix Analysis for Statistics. John Wiley \& Sons, Canada

[8] Searle, S.R. 1982. Matrix Algebra Useful for Statistics. John Wiley \& Sons, Canada 